\title{
Fostering Learning Improvements in Physics (FLIP) project: A status report
}

\section{Olivia Johnson, ${ }^{1}$ Sally Hancock, ${ }^{1}$ Judy Hardy, ${ }^{1}$ Ross Galloway, ${ }^{1}$ Marsali Wallace, ${ }^{1}$ Simon Bates ${ }^{2}$ \& Steve Draper ${ }^{3}$}

${ }^{1}$ University of Edinburgh, UK

${ }^{2}$ University of British Columbia, Canada

${ }^{3}$ University of Glasgow, UK

\section{Corresponding author:}

Judy Hardy, University of Edinburgh, UK Email: j.hardy@ed.ac.uk

\begin{abstract}
The Fostering Learning Improvements in Physics project is examining the international status of subject-based educational research in physics and the potential for work in this field to impact the teaching and learning of undergraduate physics in UK universities. While focused specifically on physics, outcomes of the project may be relevant to subject-based educational research and to teaching and learning within the physical sciences more generally. We report on the aims, approaches and current status at the mid-point of this one-year study.
\end{abstract}

Keywords: teaching and learning, physics education research

\section{Introduction}

The Fostering Learning Improvements in Physics (FLIP) project was jointly commissioned by the Institute of Physics (IOP) and the Economic and Social Research Council (ESRC) to investigate the provision for research into teaching and learning of undergraduate physics in the UK. Subject-based physics education research (PER) at higher education level is a relatively young field, with roots in studies of student difficulties with physics concepts conducted in America in the late 1970s and 1980s (McDermott 1984). Work over the next two decades established that what is taught and what is actually learned in tertiary level physics can be very different things (McDermott 1991, Redish 1994, Redish et al. 1998) and can be strongly affected by 
the pedagogical methods used (Hake 1998). Similar fields of inquiry have focused on teaching and learning in other physical science disciplines including astronomy education research and chemistry education research.

FLIP is a one-year study which aims to:

- examine the provision for, and the achievements and future potential of, PER internationally;

- understand how UK undergraduate physics teaching and learning develop in practice; and

- explore the potential for sustainable, subject-based PER at HE level in the UK and its likely impact on undergraduate teaching and learning.

Of particular interest to the FLIP project team are the multiple types of impact that could be relevant in considering the achievements and potential of PER. A high-impact study could be one that substantially advances our knowledge of how students learn physics. Such a study may have anything from a limited overall effect on the widespread practice of teaching and learning, or, when coupled with other impactful activities such as those described below, contribute significantly to changes in practice, for example, the Force Concept Inventory instrument (e.g. Hestenes et al. 1992). Another kind of high-impact contribution might result in the large-scale dissemination of evidence-based classroom innovations (e.g. Twigg 2003), while yet another might promote widespread adoption by physics instructors and/or a large-scale improvement of student attainment (e.g. Mazur 1997, Crouch \& Mazur 2001, Smith et al. 2009). The relationships between these modes of impact are not obvious and understanding them requires a review not just of PER but of the communities responsible for driving change in HE physics education in the UK.

To address these issues a cross-disciplinary team, based at the University of Edinburgh and including researchers at the University of Glasgow and the University of British Columbia, has been assembled to carry out the FLIP study. Given the likely importance of understanding the interplay between different communities of practice within the study, the team is comprised of a social scientist and a physicist with no prior experience of PER as well as PER researchers with varied backgrounds and interests.

Work began on the FLIP project in January 2013 and will continue to January 2014. At present, data collection is well under way but analysis is still in the early stages. Therefore the aim of this report is to provide an overview of the aims, approaches and current status of the project. We intend to report our findings in a future article to be published shortly after the end of the project.

\section{Research questions and methodology}

At the outset of the project, a preliminary literature review identified several recent and relevant studies of the current landscape for PER in the US. They include a PER funding census (Henderson et al. 2012), a small-scale interview-based study of physics instructors' awareness of and attitudes towards PER (Henderson \& Dancy 2008), and a large-scale study of the impact of PER on the teaching of introductory physics (Henderson \& Dancy 2009). These published studies effectively characterise the current position of PER in the US. Therefore, within the FLIP study, we have focused on collecting complementary data in three additional regions: the UK, the wider EU and Australia. In addition, we have planned a study of UK staff involved in undergraduate physics education to investigate recent and current developments in UK physics teaching, the factors supporting and challenging change, and the attitudes of physics teaching staff towards PER and teaching innovations.

The primary research questions identified for the study are:

- How does the field of PER in the UK compare to that in Europe, Australia and the United States?

- What factors have supported communities of PER practitioners capable of producing high-impact knowledge advances and/or widespread dissemination of PER knowledge advances?

- What is the relationship between PER and the diffusion of improved teaching and learning in undergraduate physics?

- How has improvement in UK undergraduate physics teaching and learning occurred in practice and which factors have encouraged and discouraged improvement?

- What are the likely necessary conditions to build and sustain a UK PER community with the capacity to foster improvements in undergraduate physics teaching and learning?

A mixed-method approach was devised to study these questions. This includes:

- a literature review, to utilise relevant, recent work on provision for and impact of PER and summarise key pieces of high-impact PER;

- a funding survey, to identify and query likely funders of PER in the UK, EU and Australia and compare findings with existing US data; 
- focus groups of UK physics instructors, to refine the approach and content of an online survey aimed at this demographic;

- online surveys of UK staff involved in undergraduate physics teaching and of PER practitioners in the UK, EU and Australia; and

- follow-up in-depth interviews, to better understand the themes which emerge from the surveys and the local context of the respondents.

In addition, substantial effort has been applied to raising the profile of the project among the UK and international physics academic communities both by direct appeals to key individuals and via a social media campaign. This includes a project blog (flipphysics.wordpress.com) for informal discussions of themes related to the project and a project Twitter profile (@FLIP_Physics).

\section{Current status}

\section{PER surveys: design and preparation}

As noted above, an initial literature review indicated that sufficient data exist from recent studies to summarise the PER landscape in the US. Online surveys were therefore designed to collect comparable data in the UK, the rest of the EU and Australia. Individuals from these regions with experience of conducting PER over the past ten years, regardless of the educational level studied, were invited to take part. Postgraduate research students were also eligible to participate. The information requested in the three surveys was essentially the same for all regions, with different versions produced only to provide region-specific options in multiple-choice questions. In addition to demographic information about the researchers and their job roles, respondents were queried on specific facets of their involvement in PER, including any funding received to carry out subject-based educational research. Additional sections probed their views of how their work on PER was placed and regarded within their department and institution, and their opinions about the regional and international supports for and achievements of PER.

As FLIP is a UK-focused study, there was some concern among the project team that researchers not based in the UK might have limited motivation to take part in the surveys. Therefore an effort was made to contact locally relevant individuals and institutions in the EU and Australia to promote the project and encourage participation in the surveys. Survey invitations were then distributed through these contacts as well as directly to contact lists amassed through systematic review of conference proceedings and departmental websites. Within the UK, a contact list for direct invitation was compiled from project team knowledge and a systematic review of UK conferences.

\section{UK physics teaching survey: design and preparation}

An additional online survey was developed for staff involved in undergraduate physics teaching in the UK. Demographic information about the respondents and their job roles was collected which is directly comparable with that collected from the PER sample. In addition, respondents to the teaching survey were asked about their attitudes towards teaching, their awareness of and attitudes towards PER, and their experience of curriculum change in undergraduate physics programmes. A final series of questions focused on the factors local to their department and/or wider institution which support and challenge innovation and excellence in teaching.

To ensure the survey was as relevant as possible, focus groups were held at three universities to refine the range of topics covered and question styles used. These discussions were extremely useful in highlighting both areas of uniformity of opinion among physics teaching staff and a wide range of institution-dependent issues and concerns. Participants also provided a great deal of useful information about what would encourage them to participate in such a study. Following suggestions by focus group participants, the survey was distributed to staff through Heads of School and/or Directors of Teaching, who were contacted prior to the survey launch and who were, on the whole, extremely supportive of the project.

\section{Survey launch and respondent demographics}

All four surveys opened on 23 April 2013 and remained open for roughly three weeks. The UK teaching and PER survey schedules are available online (see http:// www.ph.ed.ac.uk/flip/flip-surveys/flip-uk-survey-schedules). They contain a mix of tick-box and open-response questions and, with the exception of those required to determine the relevant path through the survey for each respondent, none of the questions were mandatory. At the end of the survey, respondents were asked to identify themselves if they were willing to take part in a follow-up interview. At the time of writing, preliminary analysis of the survey data has just begun, with priority given to selecting subjects for in-depth interviews. Table 1 shows the total number of respondents, and the number of respondents who volunteered for interview.

The response from UK teaching staff was extremely good, with staff at $82 \%$ of all UK physics departments participating and multiple members of staff responding from $71 \%$ of departments. All 
geographic regions of the UK and all university groups are well represented. As seen in Figure 1, there has been a particularly high response rate from senior staff. Thirty percent of respondents are

Table 1 Responses to FLIP surveys

\begin{tabular}{lcc} 
Survey & All responses & Interview candidates \\
\hline UK teaching & 281 & $63(22 \%)$ \\
UK PER & 41 & $18(44 \%)$ \\
EU PER & 85 & $34(40 \%)$ \\
AUS PER & 48 & $20(42 \%)$ \\
\hline
\end{tabular}

professors and over half have been at their institutions for over 10 years. The range of responses from the 63 staff who volunteered for follow-up interviews is largely comparable to that of the full sample of responses both demographically and thematically. Approximately 20 interviews of physics teaching staff are planned, therefore it should be possible to select a representative sub-sample to speak to in more detail.

Perhaps surprisingly, given the aims of the study, the number of respondents to the UK PER survey was the lowest of all the surveys. However, nearly half of all respondents volunteered for in-depth

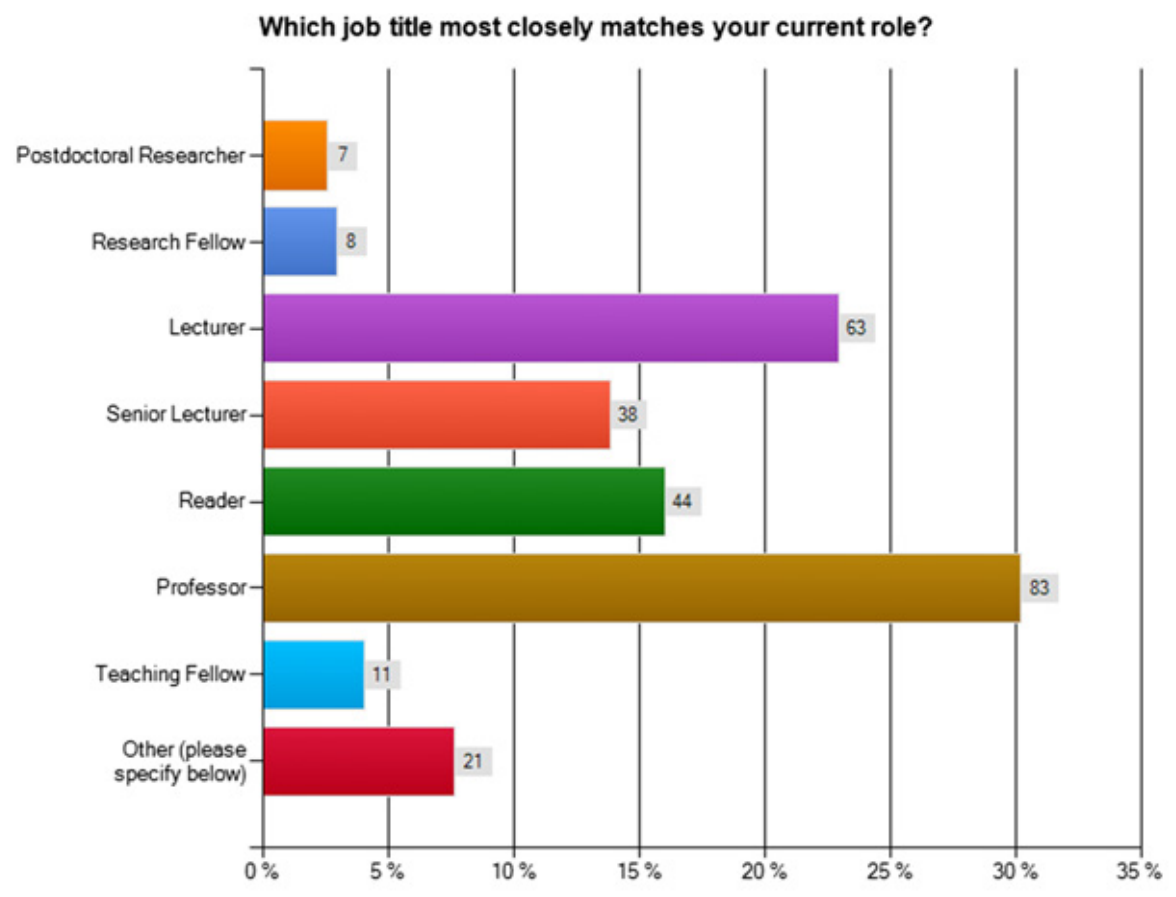

How many years have you worked at your current institution?

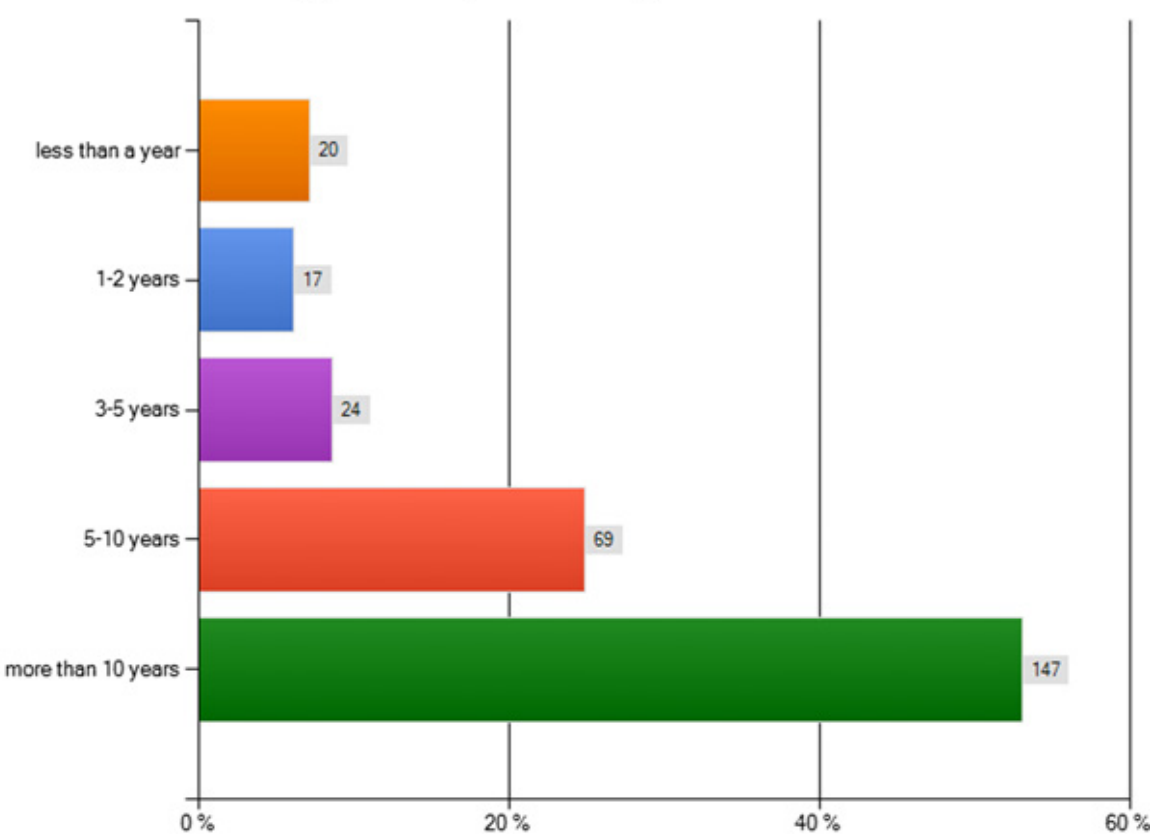

Figure 1 Demographic profile of FLIP UK physics teaching survey respondents 
interviews and we expect to contact all of these individuals.

Completion rates and overall numbers responding to the European and Australian surveys were good, giving a combined international sample of complete responses from 145 PER practitioners.

Data from surveys conducted outside the UK have not yet been examined in detail but should provide a valuable international dataset which complements extant data collected in the US. While a large number of European and Australian interviews is not planned, follow-up discussions will be held with key people in these regions to clarify the survey results where necessary, gather additional background information about the provision for and impact of PER regionally, and disseminate any outcomes of the project which could be relevant locally.

\section{Ongoing work}

As data collection via in-depth interviews is on-going for these studies at the time of writing, a discussion of preliminary findings or dominant themes arising from them would not be appropriate. However, it is possible at this stage to comment on the strength of the expected final datasets and to identify some of the issues we anticipate they will allow us to report on.

\section{Investigating PER}

Findings from the survey data will be validated and expanded upon by a series of approximately 20 in-depth interviews with PER practitioners based in the UK, as well as a smaller number of interviews with researchers in other regions internationally. Responses identifying the source and level of funding for PER research will provide a first estimate of funding available for PER and will also be used to identify the local, regional and international bodies which support this area of research. These bodies will then be queried directly about the levels of funding they have provided for PER and this information will be used to refine the estimate of PER funding in each region.

Responses identifying influential PER knowledge gains, widespread dissemination of PER-based innovations and/or evidence that PER can foster learning improvements will be used to target a review of the PER literature. This review will seek to summarise the achievements of PER, provide examples of successful dissemination and adoption strategies, and indicate the potential for improved teaching and learning. Interview data may also provide case studies related to these issues. Some of the literature exploring institutional change in $\mathrm{HE}$ (e.g. Henderson et al. 2011) may also be useful in illustrating challenges to dissemination and adoption.
Taken as a whole, the data collected and amassed by the FLIP project should allow the exploration of a broad range of topics including but not limited to:

- the prevalence of and support for PER worldwide;

- the major achievements of PER and their impact on teaching and learning;

- various national models for sustaining and utilising PER; and

- the experience, priorities and needs of UK-based PER practitioners.

\section{Investigating undergraduate physics teaching in the UK}

Findings from the UK physics teaching survey will be validated and expanded upon by a series of approximately 20 in-depth interviews of UK staff involved with undergraduate teaching. Interview candidates will be selected to represent both the broad demographic categories of the full sample of respondents and the range of views expressed with respect to teaching and subject-based educational research. Where relevant, the FLIP team may also speak to other members of staff responsible for physics teaching and departmental policy, such as technical support staff or university management, to gain a more comprehensive understanding of the local factors affecting physics teaching and learning.

Taken together, the survey responses and interviews should provide a rich dataset with which to explore a number of issues including but not limited to:

- what drives undergraduate physics programme change in UK universities, how it occurs in practice, and what benefits and challenges it brings;

- what supports and challenges excellent undergraduate physics teaching in UK universities and which departmental and institutional factors are most significant; and

- the awareness and attitudes of staff involved in undergraduate physics teaching towards PER and PER-based innovations.

\section{Fostering learning improvements in physics}

Taken in conjunction, the two strands of the FLIP project will work towards the overall goals of determining i) the likely necessary conditions to establish a sustainable PER community in the UK and ii) the potential for significant impact in terms of improving undergraduate physics teaching and learning nationwide. 
Those wishing to know more about the FLIP project as it progresses can follow the project on Twitter at @FLIP_Physics, read the online project blog at flipphysics.wordpress.com, or contact the FLIP team directly at flip@ph.ed.ac.uk.

\section{References}

Crouch, C.H. and Mazur, E. (2001) Peer Instruction: Ten years of experience and results. American Journal of Physics 69 (9), 970-977.

Hake, R.R. (1998) Interactive-engagement versus traditional methods: a six-thousand-student survey of mechanics test data for introductory physics courses. American Journal of Physics 66 (1), 64-74.

Henderson, C. and Dancy, M. (2008) Physics Faculty and Educational Researchers: Divergent Expectations as Barriers to the Diffusion of Innovations. American Journal of Physics (Physics Education Research Section) 76 (1), 79-91.

Henderson, C. and Dancy, M. (2009) The Impact of Physics Education Research on the Teaching of Introductory Quantitative Physics in the United States. Physical Review Special Topics: Physics Education Research 5 (2), 20-107.

Henderson, C., Beach, A. and Finkelstein, N. (2011) Facilitating Change in Undergraduate STEM Instructional Practices: An Analytic Review of the Literature. Journal of Research in Science Teaching 48 (8), 952-984.

Henderson, C., Barthelemy, R., Finkelstein, N. and Mestre, J. (2012) Physics Education Research Funding Census. In Proceedings of the 2011 Physics Education Research Conference.
Hestenes, D., Wells, M. and Swackhamer, G. (1992) Force concept inventory. The Physics Teacher 30 (3), 141-158.

Mazur, E. (1997) Peer Instruction: A User's Manual. Upper Saddle River: Prentice Hall.

McDermott, L.C. (1984) Research on conceptual understanding in mechanics. Physics Today 37, 24-32.

McDermott, L.C. (1991) Millikan Lecture 1990: What we teach and what is learned-Closing the gap. American Journal of Physics 59 (4), 301-315.

Redish, E.F. (1994) Implications of cognitive studies for teaching physics. American Journal of Physics 62 (9), 796-803.

Redish, E.F., Saul, J.M. and Steinberg, R.N. (1998) Student expectations in introductory physics. American Journal of Physics 66 (3), 212.

Smith, M.K., Wood, W.B., Adams, W.K., Wieman, C., Knight, J.K., Guild, N. and Su, T.T. (2009) Why peer discussion improves student performance on in-class concept questions. Science 323 (5910), 122-124.

Twigg, C.A. (2003) Models for online learning. Educause Review, 28-38. 